\title{
Kardiyak Olay Kaydedici ve Telemetri Sistemi için Yeni Bir Bileklik Tasarımı
}

\author{
Gürkan BILGIN ${ }^{(D)}{ }^{*}$, Mustafa OKTAY ${ }^{2}$, Süleyman BILGIN ${ }^{(D}$ \\ ${ }^{1}$ Burdur Mehmet Akif Ersoy Üniversitesi, Mühendislik Mimarlık Fakültesi, Burdur \\ 2Desird Tasarım AR-GE, Antalya \\ ${ }^{3}$ Akdeniz Üniversitesi, Mühendislik Fakültesi, Antalya \\ Geliş Tarihi (Received): 02.03.2021, Kabul Tarihi (Accepted): 04.04.2021 \\ $\square$ Sorumlu Yazar (Corresponding author ${ }^{*}$ ): gbilgin@mehmetakif.edu.tr \\ (C) +902482132779 등 +902482132704
}

\section{ÖZ}

Gerçekleştirilen sistem sayesinde kalp rahatsızığı olan kişilerin veya kalp rahatsızlığı olma intimali olan kişilerin takibi ve teşhisinin konulmasına yardımcı bir telemetri sistem geliştirilmiştir. Bu amaç doğrultusunda gerçekleştirilen çalışma üç bölümden oluşmaktadır. Bu bölümler sırasıyla kablosuz EKG (Elektrokardiyogram) alıcı tasarımı, Android ara yüz tasarımı ve bilgisayar ara yüzü tasarımlarıdır. Bu çalışmada vücuda yerleştirilen elektrotlar aracılığı ile alınan sinyaller yükseltip filtrelendikten sonra işlenebilir analog bir sinyale dönüştürülmüştür. Mikroişlemci yardımıyla dijitale dönüştürülen sinyal Bluetooth modülüne gönderilerek kablosuz veri iletimi sağlanmıştır. Android ara yüzü tasarımı ile kablosuz EKG alıcı devresi arasında Bluetooth bağlantısı sağlanarak EKG kayıt sistemi gerçekleştirilmiştir. Kayıt işleminin sonunda veriler hasta bilgileriyle birlikte hekim E-mail adresine yönlendirilmesi sağlanmıştır. Bilgisayar ara yüzü ile ise hekim E-mailleri otomatik kontrolü sağlanmıştır. Yeni gelen E-mailin algılanması ile hasta bilgileri ve EKG dosyası bilgisayara kaydedilip hasta EKG grafiği çizdirilmiştir.

Anahtar Kelimeler: Android arayüzü, bilgisayar arayüzü, bluetooth, EKG, telemetri

\section{A New Wristband Design for Cardiac Event Recorder and Telemetry System}

\section{ABSTRACT}

With the system implemented, a telemetry system has been developed to assist in the follow-up and diagnosis of people with heart disease or those who are likely to have heart disease. In accordance with this purpose, the study that we carried out consists of three parts. These sections are respectively: Wireless ECG receiver design, Android interface design and computer interface design. In this study, the signals received through electrodes placed on the body are amplified and filtered, and then transformed into an analog signal that can be processed. The signal that is converted to digital with the help of microprocessor is provided wireless data transmission by sending to Bluetooth module. The ECG recording system is executed by providing a Bluetooth connection between the Android interface design and the wireless ECG receiver circuit. At the end of the recording process, the data is provided to be sent to the physician's email address with the patient information. With the computer interface, Physician's Emails automatic control is provided. With the detection of the new incoming e-mail, the patient information and ECG file were saved to the computer and the patient ECG graphic was drawn.

Keywords: Android interface, computer interface, bluetooth, ECG, telemetry 


\section{GíRiş}

Teknolojinin birçok alanlarda etkisini görülmesiyle birlikte tıp alanında da gelişmeleri hızla devam etmektedir. Tıp alanında geliştirilen cihazlar ve sistemler sayesinde daha hızlı teşhis ve tedavilerinin gerçekleştirilmesine olanak sağlanmaktadır. Bu sistemlerinin başında telemetri ve teletıp sistemleri gelmektedir. Teletıp sistemlerinin gelişmesi sayesinde uzaktan hasta takibi sağlayarak hastalarının verilerini anlık takibi sağlanmasıyla birlikte hastanın tedavisi, hastalık ilerleyişinin kontrolü ve takibi kolaylaşmaktadır. Bu sistemleri kullanan hastaların en başında kalp rahatsızlığı çeken hastalar gelmektedir. İnsanoğlunun yaşamını sürdürebilmesi için gerekli organların en önemlilerinden birisi kalptir ve kalp vücudun işleyişi açısından hayati bir göreve sahiptir. Kalbin çalışmasındaki küçük aksaklıklar bile vücudun tamamını olumsuz etkileyebilmektedir. Bu durumda kalbin olası rahatsızlıklarının verdiği farklı belirtilerle erken tespiti veya durumunun gözlemlenebilmesi oldukça önem kazanmaktadır.

Kalp hastalıklarının tanı ve teşhisinde kullanılan en önemli yöntemlerin başında Elektrokardiyogram (EKG) gelir. EKG dalgalarının şekli, süresi, genliği, sinyalin periyodikliği ve sinyaller arasındaki mesafeler gibi bilgiler birçok kalp rahatsızlıklarının teşhisinde temek bilgi kaynağıdır. Kalp rahatsızlığı bulunan kişilerin veya olma intimali olan kişilerin hastalıklarının izlenmesi sürecinde EKG verilerinin sürekli olarak kaydedilmesi, EKG verilerinin değerlendirilmesi, uygun tanı ve tedavinin belirlenmesi, uygulanan tedavinin izlenerek kontrol edilmesi ve oluşabilecek komplikasyonların gözlemlenmesi açısından oldukça önem taşımaktadır. Kalp hastalıklarının tanı ve teşhisinde genellikle anlık EKG kaydı veya belirli saatler süresince kayıt alabilen Holter cihazları kullanılmaktadır. Anlık kayıtlar alındığında, hastanın ruhsal, psikolojik ve anlık fiziksel hareket durumu doğru sonuçların alınmasını etkilemektedir. Holter cihazları ile uzun süreler yapılan kayıtlar ise hekimler için fazla uzun veri anlamına gelmektedir. Hekimlerin analiz ve incelemelerinde doğru değerlendirmeyi daha rahat yapabilmesi için verinin kalitesi ve gereksiz veri fazlalığından arınması önem kazanmaktadır. Bu sayede daha kesin bir değerlendirme daha hızlı ve pratik olarak sağlanabilecektir.

Telemetri uzaktaki bir üniteyi izlemek, kontrol etmek ve parametrelerini değerlendirebilmek için kullanılan bir sistemdir. Biyotelemetri ise biyomedikal alanında vücuttan alınan işaretlerin uzaktan takibi için kullanılan bir alandır. Biyotelemetrinin kullanılmasına intiyaç duyulan durumlardan birisi de EKG işaretlerinin izlenmesidir. EKG telemetri cihazları sayesinde hastaların hastane gibi sınırlı hareket alanlarına sahip ve psikolojik yönden baskılı bir durumda alınan EKG kayıtları yerine, hasta normal yaşantısına devam ederken kayıtlar alınabilmekte ayrıca doktor tarafından uzaktan hasta kontrolü ve hasta verilerinin izlenmesi gibi durumlar sağlanabilmektedir.

Literatüre bakılırsa bu amaç doğrultusunda kardiyak sitemlerin uzaktan izlenmesi üzerine birçok çalışma bulunmaktadır. Bu çalışmalar EKG sinyalinin alınması, görüntülenmesi, kaydedilmesi, gönderilmesi ve analizi gibi birçok bölümden oluşmaktadır. EKG verilerinin alınması için klasik biyoenstrümantasyon yükselteçleri kullanılarak yapılan çalışmaların yanı sıra EKG alınması için özel üretilmiş entegreler kullanılarak yapılmış çalışmalarda bulunmaktadır (Bharathi ve Belal, 2013; Çakır, 2014). İki sistemin kendi içerilerinde avantaj ve dezavantajları bulunmasıyla birlikte entegrenin avantajları yükselteç stabiliteye sahip olması, daha küçük alan kaplaması ve elektrostatik yüklemelerden daha az etkilenmesini sayabiliriz.

EKG verilerinin kablosuz olarak alınması, iletilmesi ve görüntülenmesi gibi daha birçok çalışma bu alanın uygulama konusu içerisindedir. Kablosuz veri iletimini gerçekleştirmek için Radyo Frekansı (RF), Bluetooth, Wifi, Zigbee, GSM gibi kablosuz iletişim teknolojileri kullanılmış ve EKG verilerinin iletimini sağlanmıştır (Elena ve ark., 2002; Proulx ve ark., 2006; Zhu ve Wang, 2006; Xue ve ark., 2007; Zeybek, 2007; Aktürk, 2009; Marouf ve ark., 2017). EKG verilerinin kaydedilme ve görüntülenme ortamı bakımında farklı çalışmalara sahiptir. Bu çalışmalar dahili ekranlı, harici ekranlı, Web tabanlı, hafıza kartına kayıtlı gibi birçok çaIışmalar bulunmaktadır (Lin ve ark., 2006; Park ve Chou, 2006; Zhu ve Wang, 2006). EKG verilerinin anlık olarak görüntülenmesi üzerine yapılan çalışmalarda dahili ekran veya anlık olarak EKG verilerinin görüntülenmesini sağlayan sistemler kişilerin o andaki durumunu gözlemede kullanılmaktadır. Bu sayede kişinin acil bir müdahaleye intiyaç duyup duymadığını anlama imkânı sağlamaktadır. Ayrıca hastalık teşhisinde kullanılan kişi kayıt cihazları da bulunmaktadır. Bu anlamda, kişisel olarak kullanılan EKG cihazları iki gruba ayrılmaktadır. Bunları holter cihazları ve olay kaydedicilerdir. Holter cihazları birçok model ve özellikte bulunmakta birlikte temel olarak, en az üç elektrotun hastanın göğsüne tutturulduğu ve küçük bir taşınabilir EKG kayıt cihazlarıdır. Holter cihazları bağlandığı andan itibaren 1 ile 7 arasındaki sürekli kayıt alan EKG kaydedicidir (Zimetbaum ve Goldman, 2010). Hastalar günlük aktivitelerini gerçekleştirirken alınan bu kayıtlar hastanın semptomlarının günlük tutulmasını sağlar. Ancak hastaların duş almak, yüzmek veya aşırı mik- 
tarda terlemeye neden olan herhangi bir aktivite haricinde, kayıt sırasında elektrotların gevşemesine veya kopmasına neden olan aktivitelerin gerçekleştirmemeleri istenmektedir (Zimetbaum ve Goldman, 2010). Holter cihazının kullanım amacı, belirsiz zamanlarda gerçeklesen aralıklı aritmilerin saptanmasıdır ve anormal kalp aktivitelerinin verilerini kaydedilerek bu verilerin daha sonra incelenmesi amacıyla kullanılır. Bu verilerin gerçek zamanlı analizi henüz mümkün değildir. Gerçek zamanlı analiz yapabilmek için olay monitörü kullanılabilir (Karpawich ve ark., 1993; Wu ve ark., 2003; Hegazy ve Lotfy, 2007; Zimetbaum ve Goldman, 2010). Holter cihazların yanı sıra diğer bir kişisel EKG kayıt cihazı olay kaydedicilerdir. Bu cihazlar kendi içirişinde döngüsel ya da olay sonrası kaydediciler olarak ayrılabilir. Döngüsel kayıta, elektrotlar hastanın vücuduna sürekli olarak temas halindedir ve olay kaydetme süresi otomatik tetikleme veya gömülü algoritma tarafından tetiklenmesiyle gerçekleştirilir (Linzer ve ark., 1990; Zimetbaum ve ark., 1998).

Teknolojinin getirdiği yeniliklerden biri olan akıllı telefonların yaygın kullanımı, birçok EKG ölçümünü için akıllı telefon uygulamalarının geliştirilmesini hızlandırmıştır. Kardiyak sorunları olan hastalar veya sağlıklı insanlar, uygulamalar yardımıyla EKG sinyallerini kaydedebilmektedir. Bahsi geçen uygulamamlar Kayıt edilen EKG verilerin doktorlar ya da sağlık merkezlerine, yer ve zamandan bağımsız olarak gönderilmesine olanak sağlamaktadır. EKG verilerin kullanıcılar için kolay ve pürüzsüz hale getirmek amacıyla, teletıp sisteminde çalışması önerilmiştir (Fensli ve ark., 2005; Lucani ve ark., 2006; Lin ve ark., 2006; Lv ve ark., 2010; Tseng ve ark., 2014). Benzer çalışmalara bakılırsa Şişman EKG ve solunum ölçümlerini, gerçekleştirdikleri bir proje ile uzak bir bilgisayara yollayabilen bir algılayıcı kart üretmiş ve yazılımı geliştirilmiştir (Şişman, 2017). Kocatürk ise yakın bir çalışmada EKG işaretlerinin takibi için işaretleri $1 \mathrm{kHz}$ örnekleme frekansında örneklemiş ve IEEE 802.11.b (Wi-fi) protokolü kullanarak iletmiştir (Kocatürk, 2004). Jun Liu ve arkadaşları EKG, Solunum, vücut sıcaklığı gibi bilgileri yaptığı kablosuz giyilebilir hasta takibi cihazı çalışması ile Bluetooth 4.0 protokolünü kullanılarak bilgisayara aktarmışlardır (Liu ve ark., 2013). Çalıkuşu gerçekleştirdiği çaIışmasında EKG ve SPO2 sinyallerini enstrumantasyon yükselteçleri kullanılarak tasarlamış olduğu sistemden analizini yapmak üzere text (metin) formatında Ethernet portu kullanarak uzak bir istasyona iletmiştir (Çalıkuşu, 2012). Bir başka telemetri sistemi tasarımında Radyo Frekans (RF) modülü kullanıştır, çalışmada elde edilen veriler sayısal forma dönüştürülüp 9.6 Kps hızıyla Darbe Kod Modülasyonu (PCM) teknikleri kullanılarak uzak bir konuma gönderilmiştir (Güler ve Fidan, 2005). Boskovic ve Despotovic (2005), EKG sinyallerini iletmek için GPRS verilerini kullanan bir telemetri sistemi tasarlamışlardır. Yalman bir yaptığı tasarımda kardiyak işaretlerin mobil ara yüzde görüntülenmesi, nabız ve oksijen satürasyonlarının ölçülmesi, Vücut sıcaklığının ölçülebilmesi için Android mobil ara yüzü geliştirerek bir uygulama gerçekleştirmiştir (Yalman ve ark., 2015). Özkaraca ve Güler (2015), giyilebilir bir EKG sistemi tasarlamış, bu sistem ile sinyallerin uzaktan algılanması, alınan sinyallerin değerlendirilmesi ve hastaların durumunun izlenmesi sağlanmıştır. Buna ilaveten sisteminde tekstil kumaş elektrotlar seçilerek bunların performansları değerlendirilmiştir. Taşınabilir cihazlar ile iletişimi Bluetooth haberleşmesi ile gerçekleştirilen EKG cihazı mikroişlemci tabanlı olarak tasarlanmıştır. Chatzigiannakis ve ark. (2015), 12 kanallı, takması kolay, taşıması kolay, mobil bağlantılı, minyatürleştirilmiş otomatik EKG cihazı tasarlamış ve bir Bulut platformu hizmeti ile aktarım yapmışlardır. Sistemleri EKG verilerini tıbbı personele hem yerinde hem de uzaktan hem senkronize hem de asenkron olarak gönderme imkânı sağlamıştır. Türker ve Tarımer (2016)'da gerçekleştirdikleri bir çalışmada ise hareket sınırı olmadan EKG sinyallerini takip edebilmek için taŞınabilir EKG devresi tasarlamışlardır. Verilerin iletilmesi için Zigbee 802.11.4 standardında iletişim yapabilen KAA ile merkezi bir düğüme iletilmesi sağlanmıştır. Lee ve Seo (2019), implante edilebilir, EKG izleme sistemi geliştirmiş ve performansını değerlendirmiştir. Bu sistem yalnızca hayvanın EKG sinyalini değil, aynı zamanda ikincil hücrenin voltaj seviyesini ve implante edilebilir cihazın içindeki sıcaklığı da algılayabilmekte ve elde edilen verileri bir PC programı veya bir mobil uygulama aracılığıyla kontrol edebilmektedir (Lee ve Seo, 2019). Chandini ve ark. (2018), nesnelerin interneti (loT) platformu gömülü cihaz için Cypress kablosuz internet bağlantısına (WICED) dayalı yeni bir EKG görüntüleme metodu önermişlerdir. Oluşturdukları sistemde Raspberry Pi kullanmışlardır, topladıkları EKG verilerini Wi-Fi kullanarak doğrudan loT bulutuna iletmişlerdir. Kobay farelerinin kullanıldığı farklı bir çalışmada fizyolojik sinyallerin sürekli ölçümü için yüksek bant genişliğine sahip ( $2 \mathrm{kHz}$ örnekleme) tamamen implante edilebilir bir telemetri sistemi önerilmiştir. Önerilen sistemle kablosuz vericiden anestezi uygulanmış bir farenin EKG verileri yakalanarak sürekli olarak yüksek frekanslı ölçümler elde etme başarısına ulaşılmıştır (Russell ve ark., 2011). Bulut tabanlı çalışan bir başka telemetri tasarımında doktorlar ve hastalar için mobil uygulama gerçekleştirilmiştir. Önerilen çok amaçlı EKG telemetri cihazının mekanik tasarımı, meslekten olmayanların herhangi bir hazırlık yapmadan kuru elektrotları kullanarak olay sonrası kısa vadeli EKG sinyallerini kolayca kaydetmesine olanak tanımaktadır (Marouf ve ark., 2017). 
Bu amaç doğrultunda gerçekleştirilen çalışmada küçük ve kullanışlı bir kablosuz EKG alıcı devresi tasarımı gerçekleştirilmiştir. Alıcı devre akıllı telefonların Bluetooth bağlantısı üzerinden bağlantı yapmaktadır. Akıllı telefon içerisine yazılmış Android tabanlı bir arayüz kullanıcının EKG kaydını başlatmasına, görüntülemesine ve hekim E-mail adresine gönderilmesine imkan vermektedir. Hastaya ait EKG verilerinin görüntülenmesi için hekim bilgisayarına yüklenmek üzere hazırlamış olduğumuz arayüz aracılığıyla hekim E-mail adresi otomatik kontrolü yapılabilmektedir. Herhangi bir hastaya ait EKG dosyası hekim E-mail adresine gelmesi durumunda hasta bilgileri ve EKG dosyası otomatik olarak alınır ve sesli uyarı sistemiyle birlikte hasta EKG görüntüsü ekranda görüntülenmesi sağlanmaktadır. Gerçekleştirilen sistem hastaların hayatlarını kısıtlamadan net ve doğru EKG sinyallerinin elde edilmesini sağladığı gibi, hekimlerin bu sinyallere uzaktan ulaşabilmesi tanı ve tedavi sürelerini azalmasına yardımcı olmaktadır. Uzun kayıtlar alınarak oluşan zaman ve bilgi fazlalığını ortadan kaldıran bu sistem, hasta ile hekim arasında kullanılmak üzere tasarlanmıştır. Ayrıca bu sistem, kalp rahatsızlığı olma ihtimali olan kişilerin erken teşhisine yardımcı olmakta, kalp rahatsızı̆̆ı olan kişilerin takip ve tedavi sürecinin izlenmesi konusunda kolaylık sağlamaktadır. Bu sayede hekimler uzun Holter kayıtlarını incelemek yerine hastalarını rahatsızlık hissettikleri andaki kayıtlarını inceleyerek teşhis koyma sürecini kısaltabilecek ve hastanın tedavi sürecinin hızlanmasına olanak sağlayabilecektir.

\section{MATERYAL VE YÖNTEM}

Gerçekleştirilen bu çalışma ile kalp rahatsızlığı bulunan kişilerin takibi veya kalp rahatsızığı olma ihtimali olan kişilerin doğru teşhis ve tedavisinin sağlanması amaçlamaktadır. Bu amaçla gerçekleştirilen sistem 3 bölümden oluşmaktadır. Bu bölümler Şekil 1' de görüldüğü gibi kablosuz EKG tasarımı, Android ara yüzü oluşturma ve bilgisayar ara yüzü olmak üzere 3 bölümden oluşmaktadır.

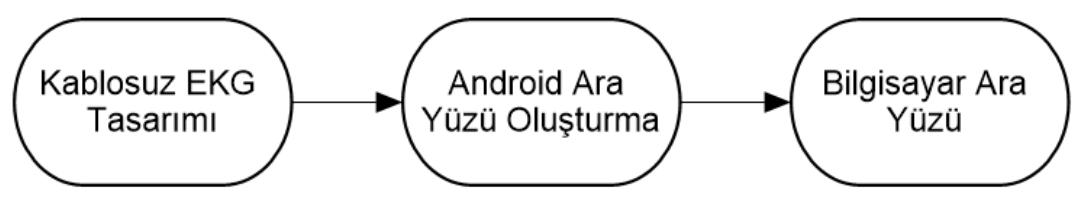

Şekil 1. Gerçekleştirilen sistem bölümleri

İlk bölümde kablosuz EKG tasarımı yapılmıştır. Burada EKG verilerini alabilmek için vücudun belirli noktalarını yerleştirilen elektrotlar aracılığı ile alınan veriler alıcı devresi tasarlanarak işlenmiş ve kablosuz veri iletişimlerinden Bluetooth modülü aracılığı ile verilerin akıllı telefona yönlendirilmesi sağlanmıştır.

İkinci bölümde ise Android tabanlı ara yüz geliştirilerek kullanıcıya sunulmuştur. Kablosuz olarak EKG verilerinin akıllı telefonda görüntülenmesi, kaydedilmesi ve
GSM teknolojisi kullanılarak verilerin hekim E-Mail adresine yönlendirilmesi sağlanmıştır.

Son bölümde ise bir bilgisayar ara yüzü oluşturulmuştur. Bu bölümde akıllı telefon ile E-mail ortamına yönlendirilen EKG kaydı bilgisayar ara yüzü ile otomatik olarak hekim E-mailleri kontrolü sağlanmıştır. Hekim E-mail adresine gelen EKG verilerinin sesli uyarı sistemi ikazı ile birlikte ara yüz ekranında EKG grafiğinin görüntülenmesi sağlanmıştır. Gerçekleştirilen sistemin genel bir görüntüsü Şekil 2' de verilmiştir. 


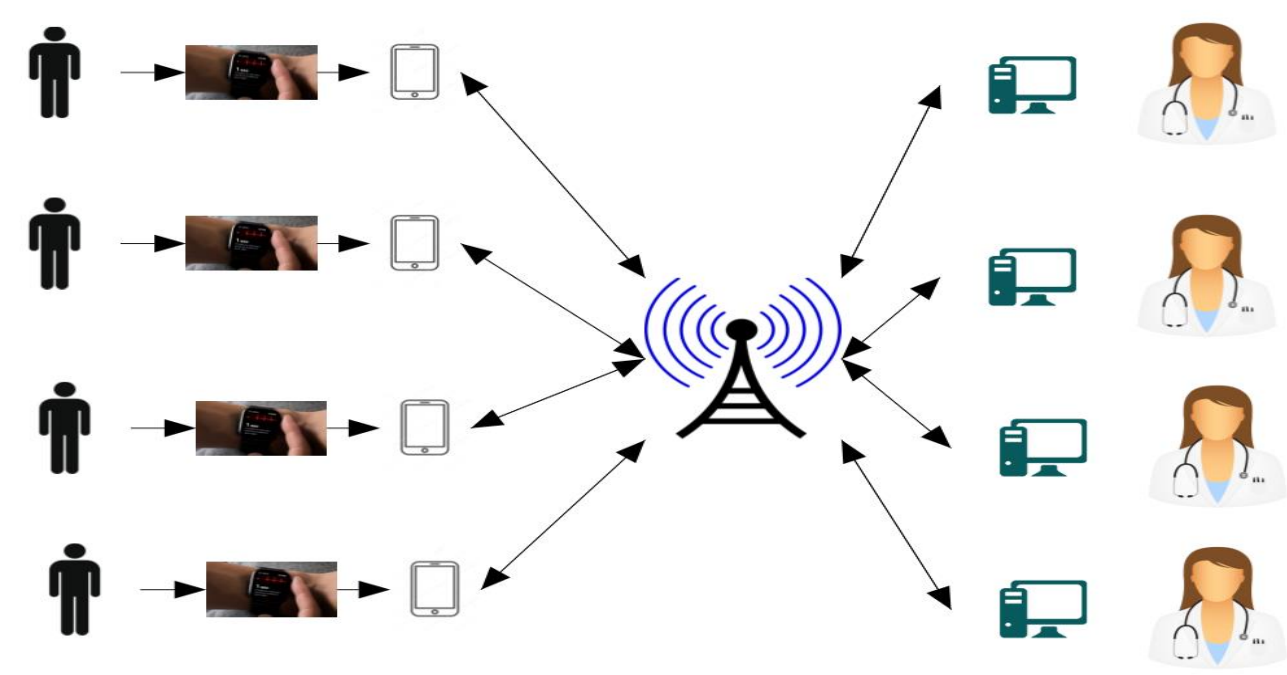

Şekil 2. Gerçekleştirilen sistemin genel görüntüsü

\section{Kablosuz EKG Tasarımı}

Çalışmadaki EKG alma işlemi 5 bölümden oluşmaktadır (Şekil 3). Bunlar sırasıyla elektrotların vücudun doğru noktalarına yerleştirilmesi, elektrotlardan alınan sinyalin enstrümantasyon yükselteçler tarafından yükseltilmesi, yükseltilen sinyal üzerindeki istenmeyen parazit ve diğer sinyallerin filtrelenmesi, parazitten arındırılmış EKG sinyalinin dijitale dönüştürülmesi ve bu sinyalin görüntülenmesi veya gönderilmesi gibi bölümlerden oluşmaktadır.

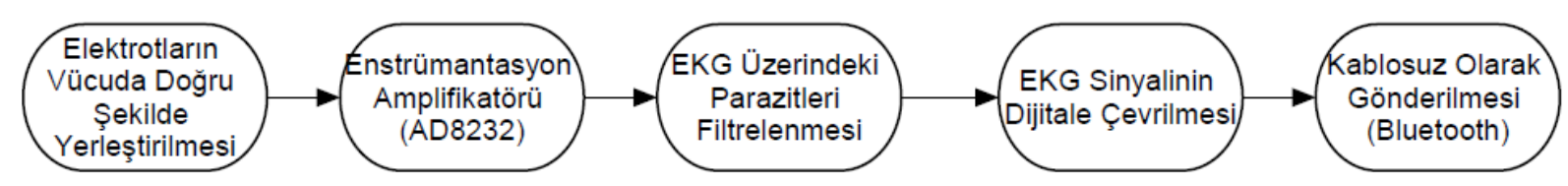

Şekil 3. Kablosuz EKG tasarımı

\section{Elektrotların Vücuda Yerleştirilmesi}

Insan kalbi elektriksel aktivasyonu üç boyutlu olarak gerçekleşmektedir. Bu aktivasyonu en iyi şeklide göre bilmek için vücudun farklı noktalarına yerleştirilen elektrotlar kalbi farklı açılardan gördükleri için bir elektrotta fark edilemeyen elektriksel aktivasyonun diğer elektrotlarda tespit edilebilmesi sağlanır (Cunedioğlu, 2007). Basit bir EKG sinyali alabilmek için elektrotların yapıştırılacağı en uygun noktaları Eindhoven Üçgeni olacak şekilde elektrotlar yapıştırıımalıdır. Eindhoven Üçgeni kalbi merkeze alarak eşkenar üçgenin oluşturacak şekilde elektrotların vücuda yerleştirilmesidir. Oluşturulan bu üçken kalbi en iyi şekilde anlamamızı olanak sağlamaktadır.
Elektrotların vücudun belirli noktaların haricinde yerleştirilmesi oluşan EKG grafiğinin yanlış sonuç elde edilmesine neden olacaktır. EKG sinyallerinde değişiklik olması hekimlerin yanılmasına ve grafiği yanlış yorumlamasına neden olacaktır. Bu çalışmada standart EKG derivasyonlarından olan Bipolar derivasyonu seçilmiştir. İlk tanı aşamasında en çok kullanılan EKG sinyalidir. Elektrot yerleşimine ait, tek kanallı LA-RA (Lead I) Şekil 4' te gösterilmiştir. 


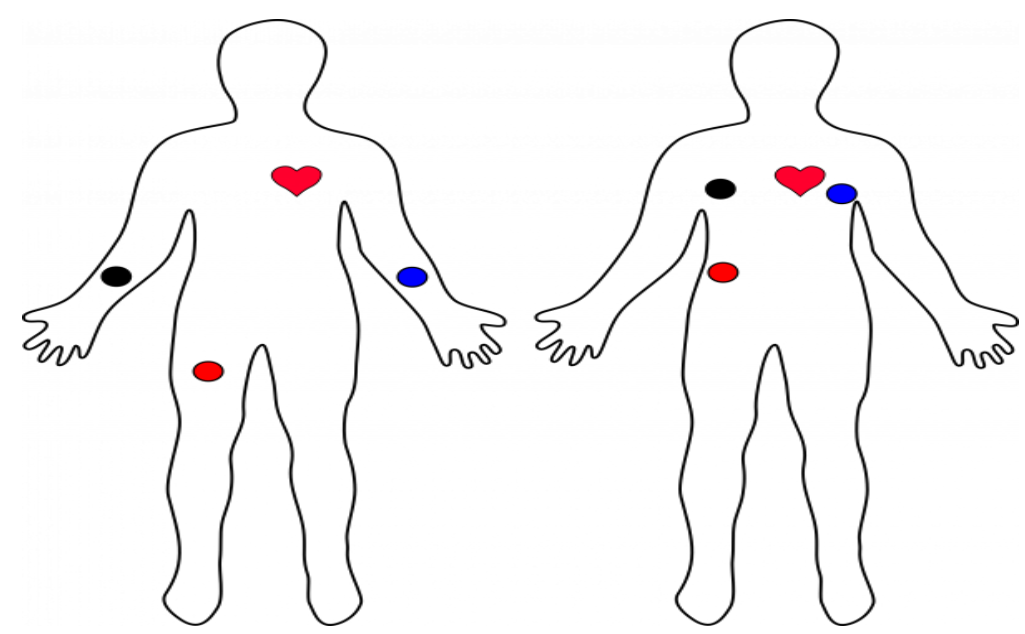

Şekil 4. LA-RA (Lead I) göre elektrot yerleştirilecek noktalar

Çalışma süresince, tek kullanımlık ve hijyen olmasının yanı sıra tedarik edilmesi, kullanılması ve yerleştirilmesi bakımdan kolay olması sebebiyle vücuda yerleştirilen $\mathrm{Ag} / \mathrm{AgCl}$ elektrotları kullanılmıştır.

\section{Enstrumantasyon için AD8232 Entegresi Özellikleri ve Kullanılması}

Analog Device firmasının üretmiş olduğu AD8232 entegresi kalp atış hızı monitörü olarak kullanılabilen ve kalbin elektriksel aktivitesini ölçmek için kullanılan uygun maliyetli bir enstrümantasyon amplifikatör entegresidir. Entegre içerisinde bir enstrümantasyon amplifikatörü, bir operasyonel amplifikatör, bir sağ bacak sürücü amplifikatörü ve bir midsupply referans tamponu bulunmaktadır. Buna ek olarak, AD8232 entegresinde lead off (elektrot algılama) algılama devresi bulunmakta ve lead' lerin tekrar bağlantısı sağlandıktan kısa bir süre sonra sinyali geri getiren otomatik hızlı geri yükleme devresi içermektedir. AD8232'deki enstrümantasyon amplifikatörü, giriş sinyallerine kazanç uygulamak ve eş zamanlı olarak sinyallerini filtrelemek için tasarlanmıştır. Bu özellik, küçük bir EKG sinyalini 100'lük bir faktörle yükseltmeyi ve $\pm 300 \mathrm{mV}$ kadar büyük elektrot kaymalarını reddetmesini sağlar. Offset reddetme elde etmek için, Şekil 5 ' te gösterildiği gibi, enstrümantasyon amplifikatörü, HPSENSE ve HPDRIVE çıkışı uçları arasına bir RC devresi bağlanmıştır.

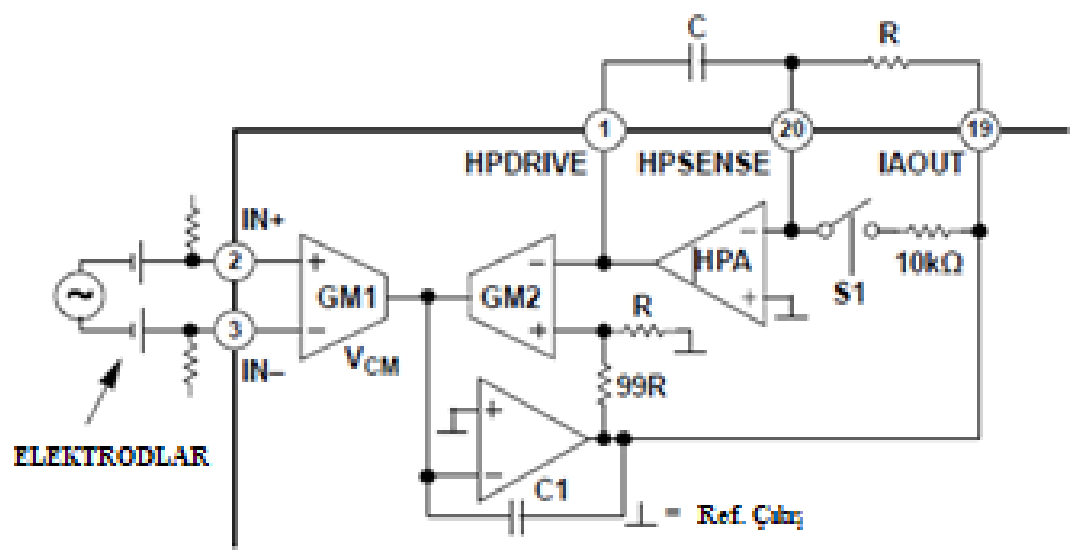

Şekil 5. Offset reddetme elde etmek için RC bağlantısı (Analog Devices, 2021) 
Elektrotların vücudun doğru noktalarına yerleştirildikten sonra bu elektrotların uçları AD8232 entegresinde özel olarak tayin edilmiş olan +IN, -IN ve RLD pinlerine girilmiştir. Entegre içerisinde $\mathrm{mV}$ seviyesindeki EKG sinyali yükseltilerek IAOUT pininden çıkmaktadır. Yükseltme sırasında gürültü ve parazitlerinde yükseltilmesinden dolayı çıkan sinyalin filtrelenmesi gerekmektedir. Bunun için AD8232 entegresi içerisinde bulunan dahili opamp sayesinde filtre tasarımı yapma imkânı sağlamaktadır. Buraya bağlanılacak olan uygun direnç ve kondansatör değerleri filtre tasarımı yapmaya ve çıkışından düzgün bir EKG sinyali almaya olanak sağlamaktadır. Şekil 6.' da AD8232 entegresinin EKG devresinin şeması görülmektedir (Analog Devices, 2021).

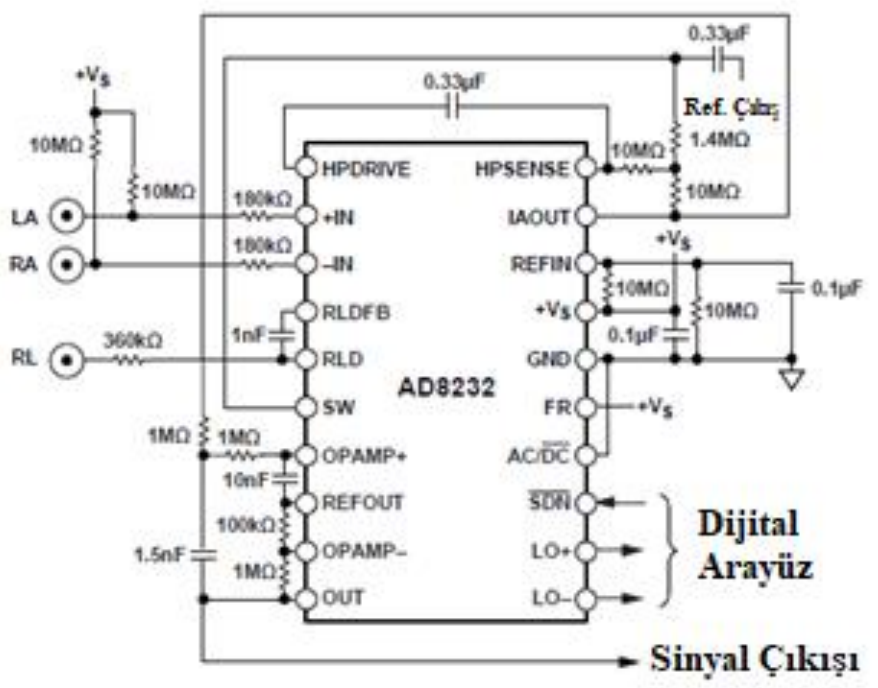

Şekil 6. AD8232 entegresinin EKG devresinin şeması (Analog Devices, 2021)

\section{ADC Dönüşümü ve EKG Sinyalinin Dijitale Dönüştürülmesi}

AD8232 Entegresinin çıkış ucundan alınan EKG sinyalini dijital sinyale dönüştürmek için ADC kullanılmıştır. Günümüzde içerisinde dahili olarak bulunan mikrodenetleyici ve mikroişlemciler bulunmaktadır (Analog Devices, 2021). Mikrodenetleyiciler sayesinde ADC dönüştürme işlemleri çok daha az maliyetli ve kontrolü kolay bir hale gelmiştir. Bu çalışmada yaygın ve uygun maliyetli bir mikro denetleyici olan Atmega328 entegresi kullanılmıştır. Microdenetleyici ile ADC sinyal dönüşümünde önemli olan iki durum vardır. Bunlar sinyalin örnekleme çözünürlüğü ve örnekleme frekansıdır.

ADC' nin dijital bilgiye dönüştürebildiği en küçük gerilim değerine adım büyüklüğü denmektedir. Adım büyüklüğü $1 \mathrm{LSb}$ değeri olarak da ifade edilir. Adım büklüğünün matematiksel ifadesi Denklem 1' de görülmektedir.

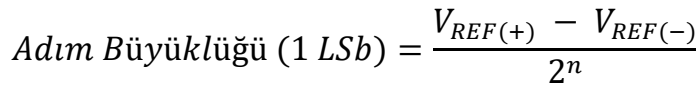

Adım aralığı ne kadar küçük olursa EKG sinyali ters orantılı olarak artmaktadır ve sinyalin gerçek değer yakın alınması sağlanmaktadır. Bu çalışmada kullanılan Atmega328 mikrodenetleyicide 6 adet 10 bit çözünürlüğünde $A D C$ pini bulunmaktadır. Bu pinler aracığı ile maksimumu $5 \mathrm{~V}$ genliğindeki bir EKG sinyalini ADC referans voltajlarını $\operatorname{VREF}(+)=\operatorname{VCC}$ ve $\operatorname{VREF}(-)=G N D$ olacak şekilde alınırsa adım aralığı Denklem 1' e göre;

$$
\frac{5 V-0 V}{2^{10}}=0,0048828125 \mathrm{~V}
$$

olarak hesaplanır ve bu yaklaşık olarak $4,88 \mathrm{mV}$ adım aralığına sahip bir örnekleme olanağı sağlayabileceğini ifade etmektedir. Bu değer analog bir EKG sinyalini dijital modellemek için yeterli bir aralıktır. Aşağıda örnek 4 bitlik bir çözünürlük modellemesi Şekil 7' de gösterilmiştir. 


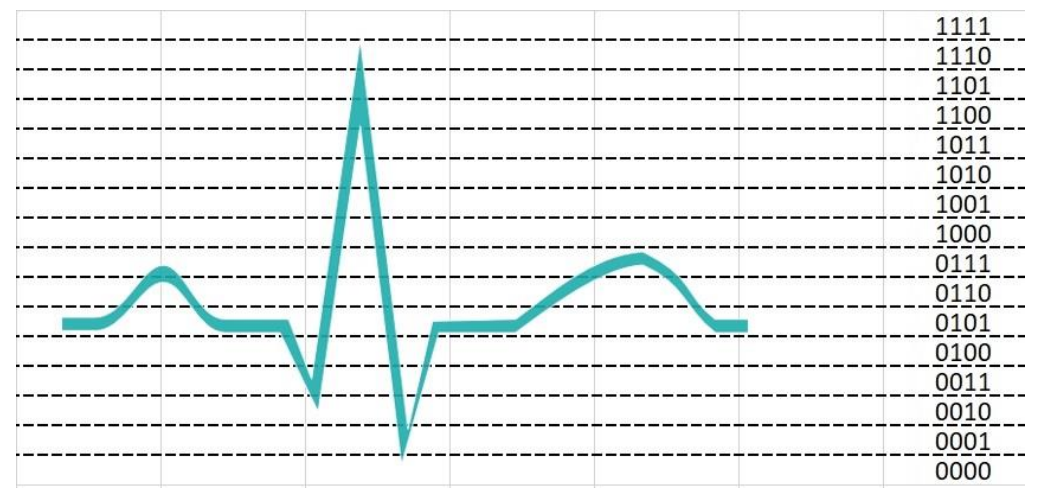

Şekil 7. EKG sinyalinin 4 bitlik çözünürlükteki modellenmesi

\section{Dijital verilerin Gönderilmesi}

Kablosuz olarak veri iletimini sağlamak için Bluetooth modülü olarak Guangzhou HC Information Technology firmasının $\mathrm{HC}-06$ modeli kullanılmıştır. $\mathrm{HC}$ Standart $\mathrm{HCl}$ Bağlantı Noktasına (UART veya USB) sahip, iletişimdeki akımı $8 \mathrm{~mA}$ olan bu modül $2.4 \mathrm{GHz}$ dijital kablosuz alıcıvericiye sahiptir. Kullanılan Bluetooth modülü Şekil 8.' de görülmektedir.
Mikrodenetleyici ile Bluetooth modülü arasında ve Bluetooth modülü ile Android arasında bir bağlantı protokolü oluşturulmuştur. Bu protokol oluşturulurken gönderilecek verinin bit olarak uzunluğu ve gönderim hızı önemlidir. Mikro denetleyici ile Bluetooth modülü arasındaki haberleşme UART (Universal Asynchronous Receiver Transmitter) haberleşme protokolüne bağlı olarak gerçekleştirilmiştir. Asenkron olarak çalıştığı için herhangi bir "clock" intiyacı duymaz ve baud rate ayarları sayesinde karşılıklı olarak veri gönderme hızları ayarlanmıştır. Şekil 9.'da iki UART haberleşmesine sahip cihazın bağlantı şeması gösterilmektedir (Keskin, 2018).

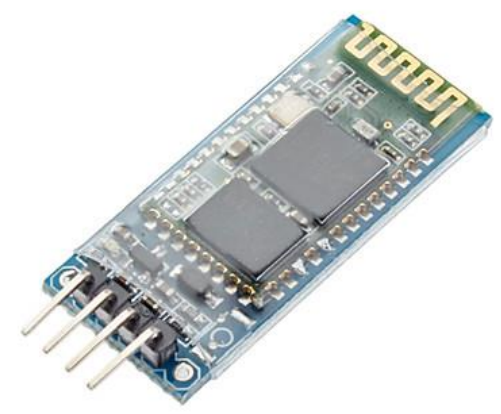

Şekil 8. HC-06 bluetooth modülü

\section{MCU}

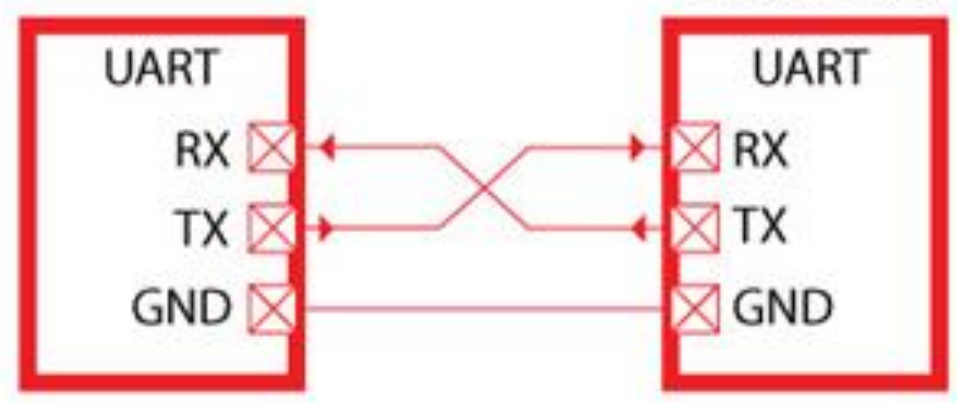

Şekil 9. UART haberleşme bağlantısı 
Mahdiani ve ark. (2015) yaptıkları çalışmada EKG sinyalinin örnekleme hızı $50 \mathrm{~Hz}$ ye eşit olduğunda bile, HRV parametrelerinin makul bir hata ile neredeyse doğru olduğunu göstermişlerdir (Shadi 2015). Normal PhysioNet MIT-BIH Arrythmia veri bankasından alınan EKG sinyallerine göre ideal bir örnekleme frekansı 360 $\mathrm{Hz}$ olarak almaktadırlar.

\section{Bilgilendirme Ekranı}

Çeşitli boy ve renklerde üretilen ekranlar kullanım yerlerine göre özenle seçilmektedir. Bu seçim sırasında kullanılacak ortamın özelliği, ekranın büyüklüğü, enerji tü- ketimi ve maliyeti gibi birçok etken göz önünde bulundurulmaktadır. Bu amaç doğrultusunda çalışmada daha düşük enerji tüketimi ve daha az yer kaplaması nedeniyle Organik ışıma yayan diyotlar (OLED) ile tasarlanış ekran kullanılmıştır. Şekil 10' da kullanılan OLED ekran görülmektedir.

\section{Program Akış Diyagramı ve Devre Kartı}

Bu çalışmada tasarlanan EKG alıcı devresinin akış diyagramı Şekil 11' de gösterilmiştir. Şekil 12' de ise tasarlanan devre kartının ön ve arka yüzünün görüntüsü verilmiştir.

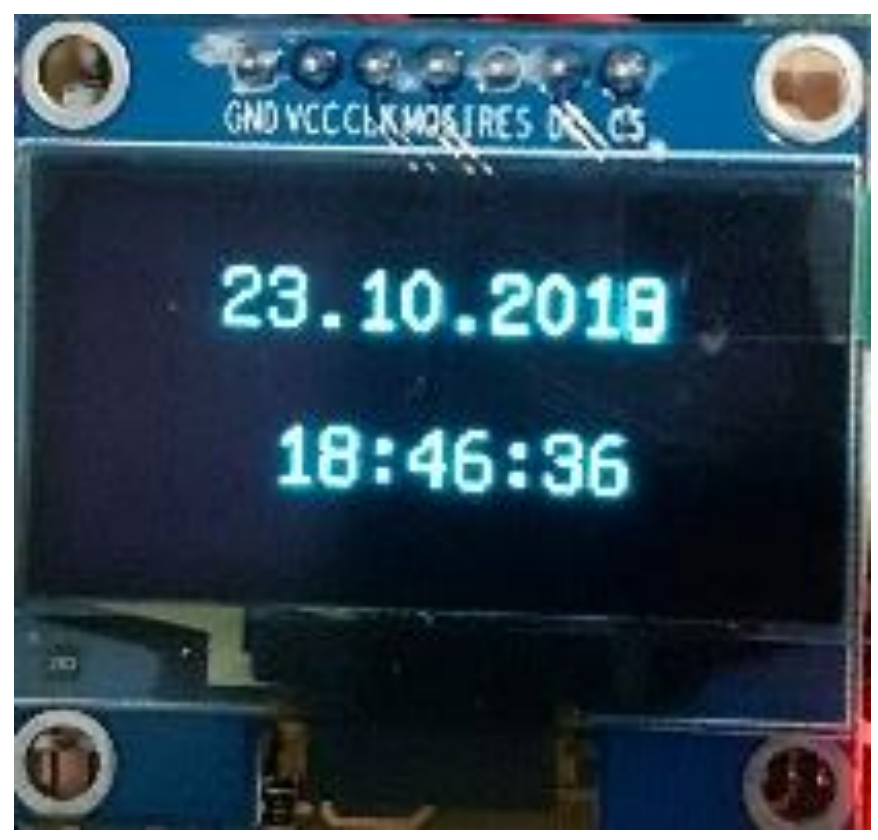

Şekil 10. Kullanılan OLED ekran 


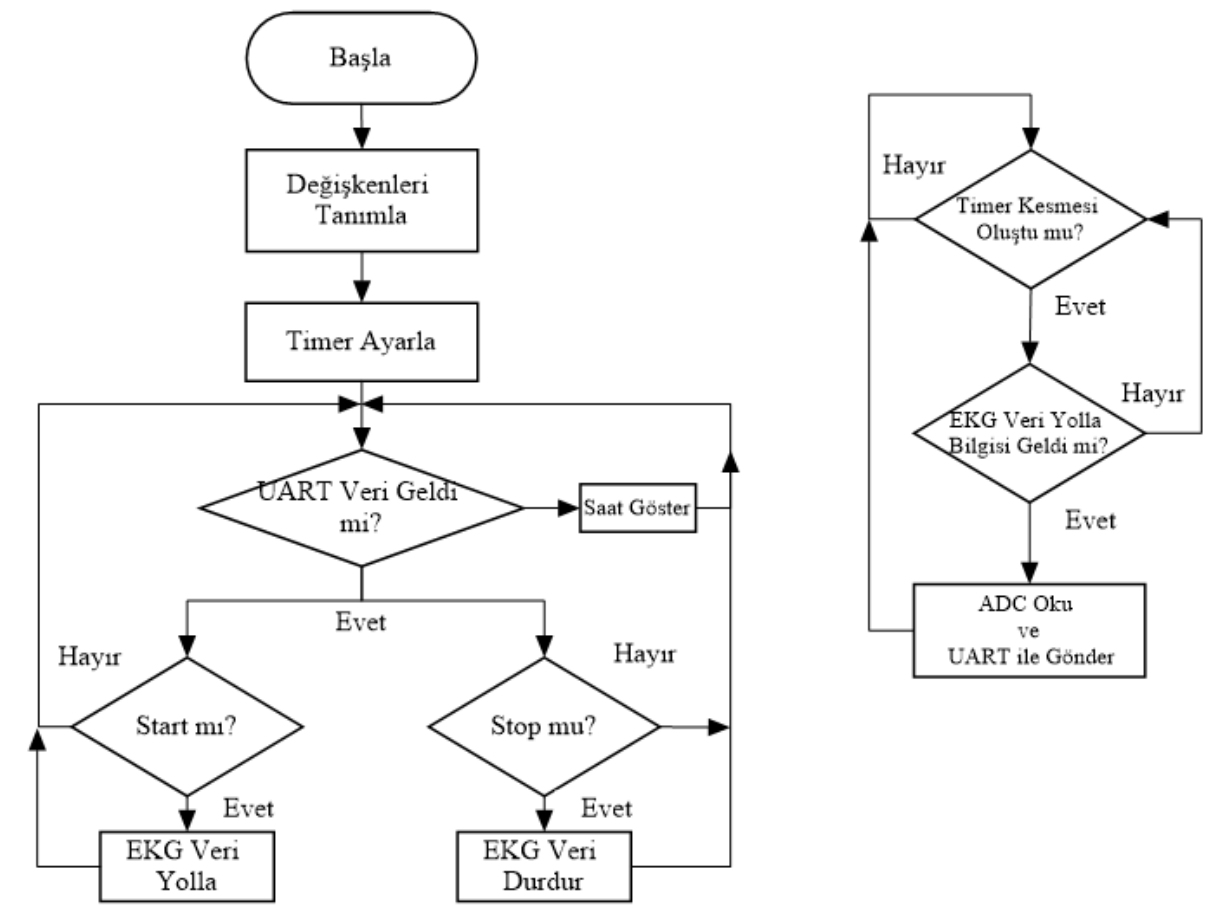

Şekil 11. EKG alıcı devresi program akış diyagramı

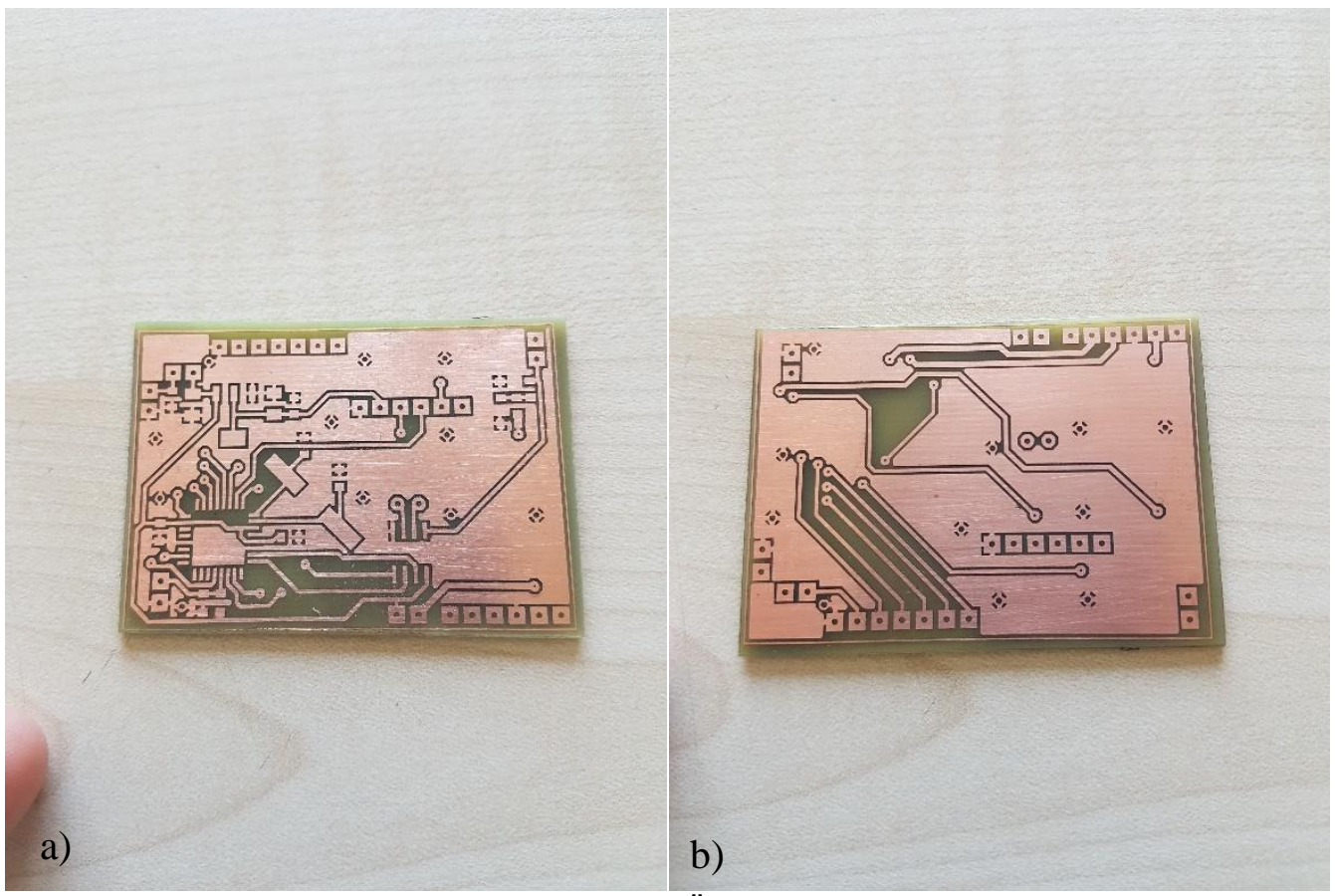

Şekil 12. EKG alıcı devre kartı a) Üst görünümü, b) Alt görünümü 
Son olarak tasarlanan devrenin elektrotlar ile kullanımı ve kutulanmış olarak görüntüsü Şekil 13'te verilmiştir.
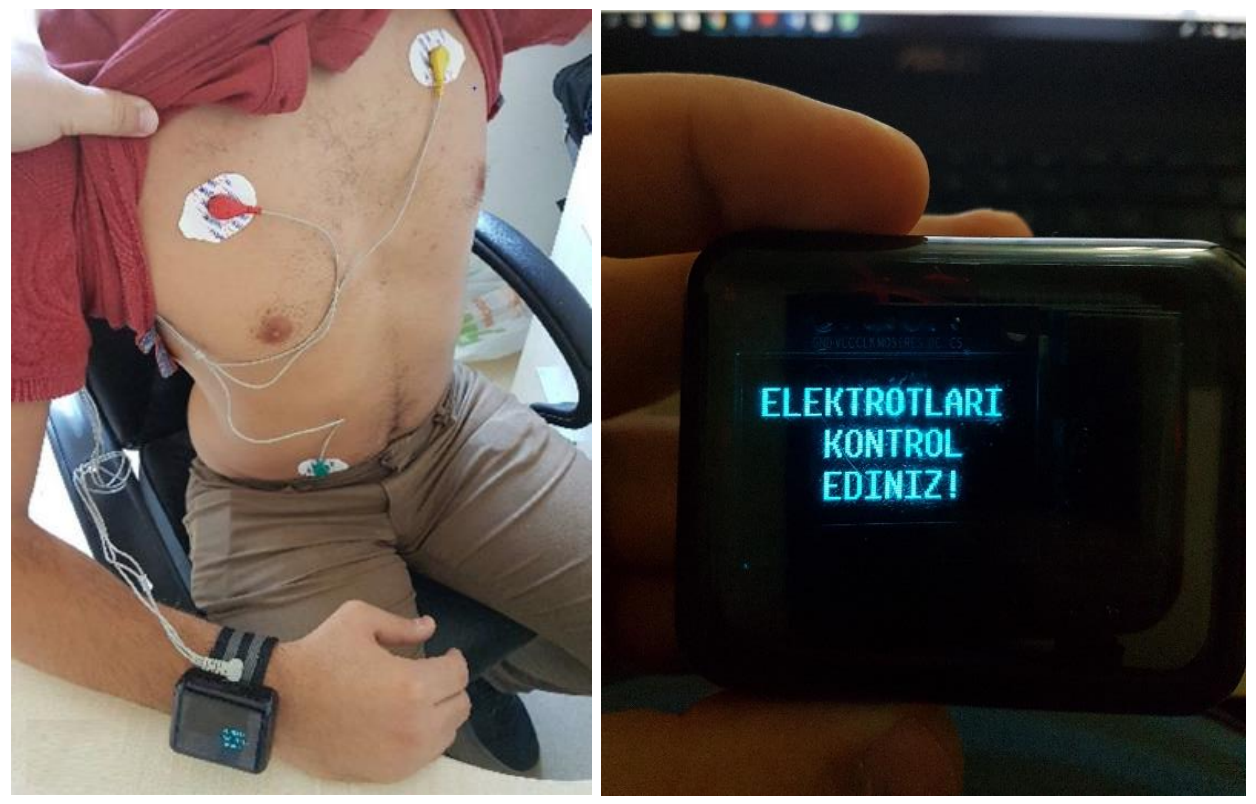

Şekil 13. Kablosuz EKG alıcı devrenin elektrotlar ile kullanılması ve kutulanması

\section{Android Ara Yüz Oluşturulması}

Google firması tarafından geliştirilen Android yazılımı, kullanıcıya büyük kolaylıklar sağlayan görsel bir işletim sistemidir. Tabletler ve cep telefonları gibi günlük hayatın büyük parçası olan cihazlarda kullanılması bu işletim sistemini popüler hale getirmiştir. Bu çalışmada popüler bir işletim sistemi olmasının yanı sıra milyonlarca kullanıcı olması sebebiyle Android ara yüzü kullanılmıştır.
Popüler bir yazılım olması nedeniyle kaynak bulmak daha kolaydır ve benzer çalışmaların bulunması konusunda geniş bir çalışma alanına sahip olması dolayısı ile yazılımın geliştirilmesi kolaylaşmaktadır. EKG verilerinin izlenebilmesi için çalışmada gerçekleştirilen ara yüz, Android işletim sistemi olan tüm cihazlarda çalışabilmektedir. Gerçekleştirilmiş olunan Android ara yüz uygulaması Şekil 14' te gösterilmiştir.

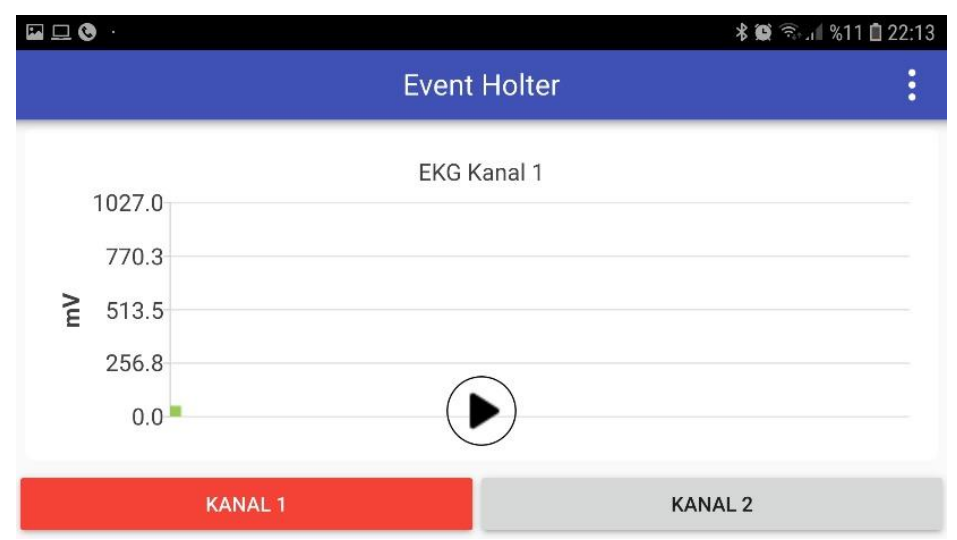

Şekil 14. Olay kaydedicisi Android ara yüz görünümü

Gerçekleştirilen sistem açıldığı anda kurulmuş olduğu Android cihazın Bluetooth bağlantısını direkt olarak açarak çevredeki Bluetooth cihazlarını taramaya başlamaktadır. Kablosuz EKG devresi ile eşleşme işlemi biti- 
rildikten sonra cihazdan veri almak üzere hazır beklemektedir. Şekil 15'te Bluetooth bağlantı ekranı görüntüsü görülmektedir.

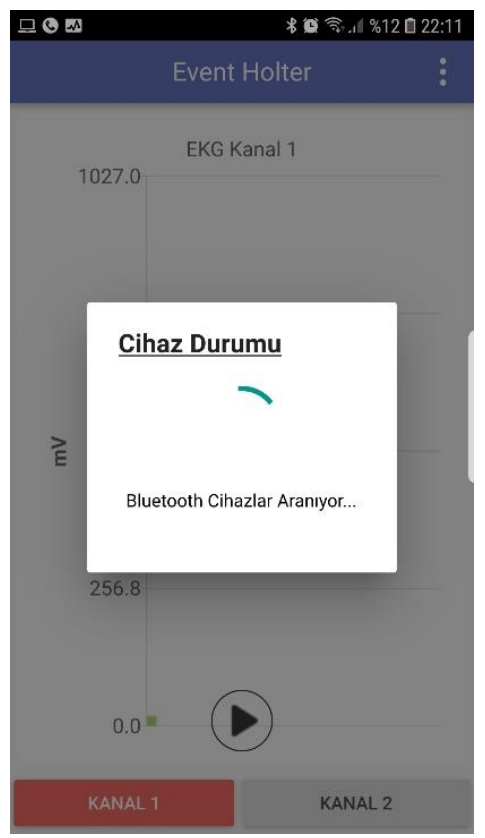

Şekil 15. Bluetooth cihaz ekran görünümü

İki cihaz arasında bağlantı sağlandıktan sonra kullanıcının EKG verisinin alınması için ekran üzerinde bulunan "Kaydet" düğmesine basarak EKG verilerini almaya başlamakta ve gerçek zamanlı olarak grafiği ekranda göstermektedir. Bu sayede kişi kendi kalp ritmini anlık olarak görebilmekte ve kaydını gerçekleştirebilmektedir. Kayıt işlemini bitirmek için ise yine ekranda bulunan "Durdur" butonuna tıklayarak kayıt işlemini durdurmuş olur. Şekil 16 'da kayıt ekranı görülmektedir.

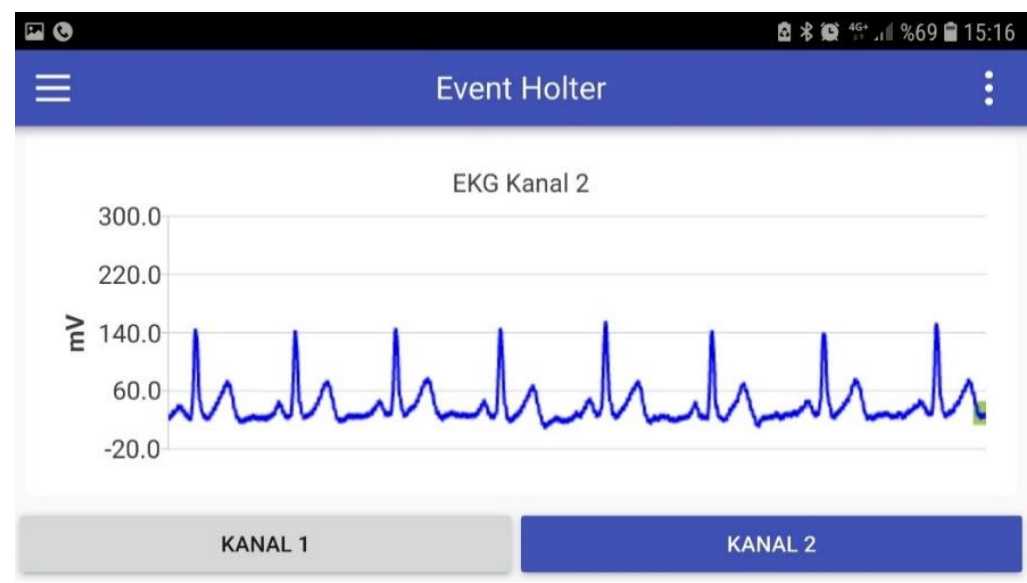

Şekil 16. EKG kayıt ekranı

Sistem kayıt işlemi tamamlandığında oluşturulmuş olunan EKG dosyasını hekim E-mail adresine yönlendirmek üzere paylaşım ekranını açmaktadır. Burada otomatik olarak oluşturulan E-mail formatı sayesinde hasta bilgileri ve EKG kayıt dosyaları hekim E-mail adresine gönderilmek üzere hazırlanmaktadır. Kullanıcı gönder tuşuna basarak tüm işlemin tamamlanmasını sağlayarak 
bir sonraki kaydetme işlemine kadar program hazır olarak beklemektedir. Şekil 17'de E-mail gönderme ekranı görülmektedir.

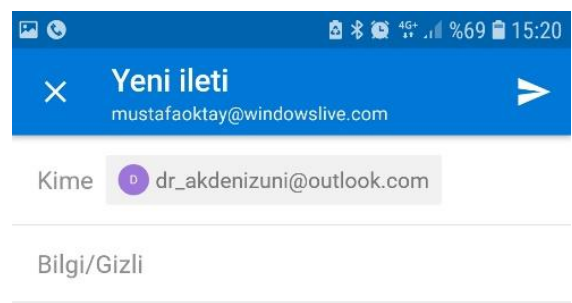

Mustafa OKTAY Adlı Hastanın EKG Kaydı

\begin{tabular}{|c|c|}
\hline 曲 & $\begin{array}{l}\text { 04_09_2018_15_18_29.csv } \\
268 \mathrm{~KB}\end{array}$ \\
\hline \multicolumn{2}{|c|}{ Merhaba Akdeniz Üniversitesi Bey/Hanım } \\
\hline $\begin{array}{l}04 / 0 \\
\text { ollçür } \\
\text { Kont }\end{array}$ & $\begin{array}{l}2018 \text { 15:18:29 tarihinde aldığım EKG } \\
\text { i ektedir. } \\
\text { l eder misiniz? }\end{array}$ \\
\hline
\end{tabular}

Android için Outlook uygulamasını edinin

Şekil 17. E-Mail gönderme ekranı görünümü

\section{Bilgisayar Ara Yüz Oluşturulması}

Kablosuz EKG alıcı devresi ile Android ara yüzü uygulaması arasında bağlantı sağlanıp EKG verisi hekim EMail adresine yönlendirildiğinde, hekimin hasta EKG verilerini incelemesi için bilgisayarda bir ara yüz tasarımı gerçekleştirilmiştir. Şekil 18.' de bilgisayar ara yüzü görülmektedir.

Gerçekleştirilen bilgisayar ara yüzünün otomatik E-Mail kontrolü akış diyagramı Şekil 19'da görülmektedir.

Program online olarak bilgisayara tanımlanmış olan Email adresini kontrol etmektedir. Program gelen e-mailleri her 30 saniyede bir kontrol etmektedir. Eğer herhangi bir yeni e-mail gelmiş ise bu maili kendi verilerine çekip mailin tasarlanan Android ara yüzünden gelip gelmediğine karar vermektedir. Eğer gelen e-mail kendi programından ise hasta bilgilerini alarak EKG grafiğini program üzerinde bulunan çizim alanına çizmektedir. Çizilen EKG grafiğinin üstüne hangi hastadan geldiği yazılmaktadır. Çizim işlemi bittiğinde hekime yeni verinin geldiğini belirtmek üzere bilgisayar hoparlöründen sesli ikaz vermektedir. Bu sesli sinyal sayesinde hekimin uyarılması amaçlanmıştır. Her gelen mail dosyaları masa üstünde bulunan bir klasöre kaydedilmektedir. Hekim buradan dosyalar arasından herhangi bir EKG verisini açmak ve incelemek isterse program üzerinde bulunan "Dosya Aç" butonunu tıklayarak dosya uzantısına gidip dosyayı açabilir "Verileri Çiz" butonuna tıklayarak çizim alanına çizilmesini sağlayabilmektedir. Şekil 20 'de yeni gelen e-mail in otomatik olarak ekranda çizdirilmiş hali görülmektedir. 


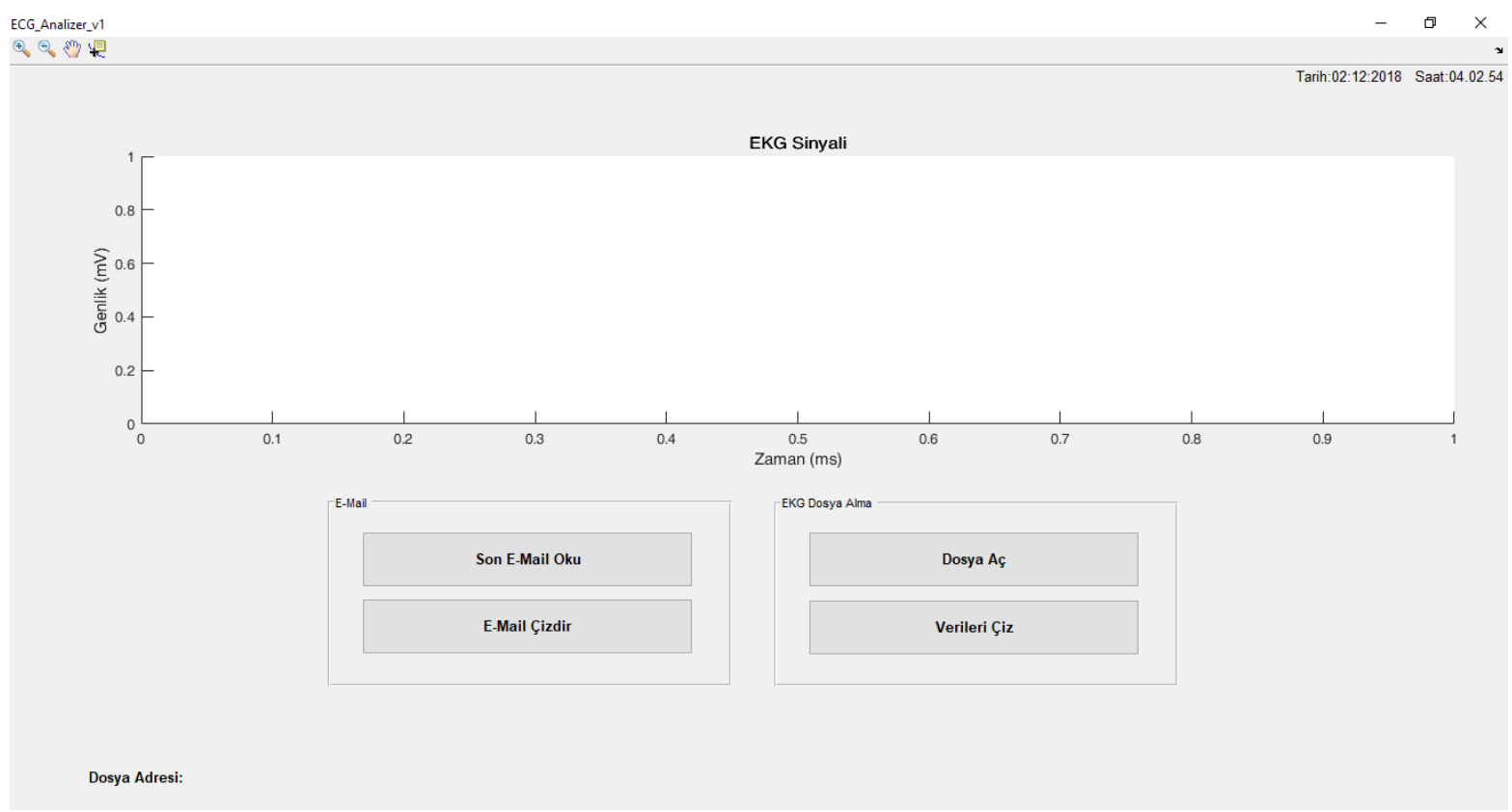

Şekil 18. Bilgisayar ara yüzü görünümü

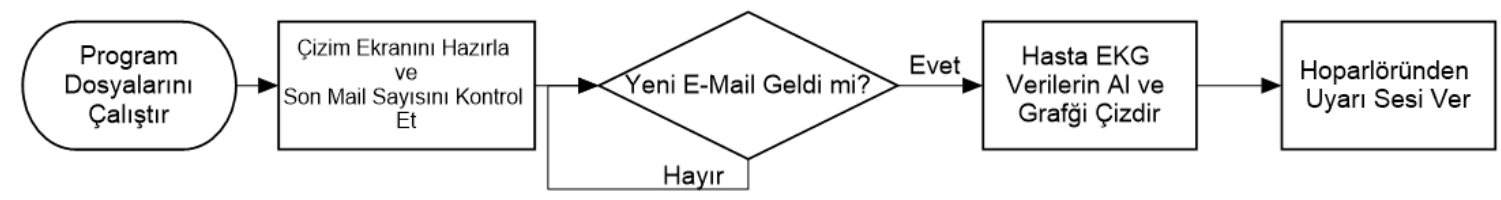

Şekil 19. Bilgisayara ara yüzü akış diyagramı

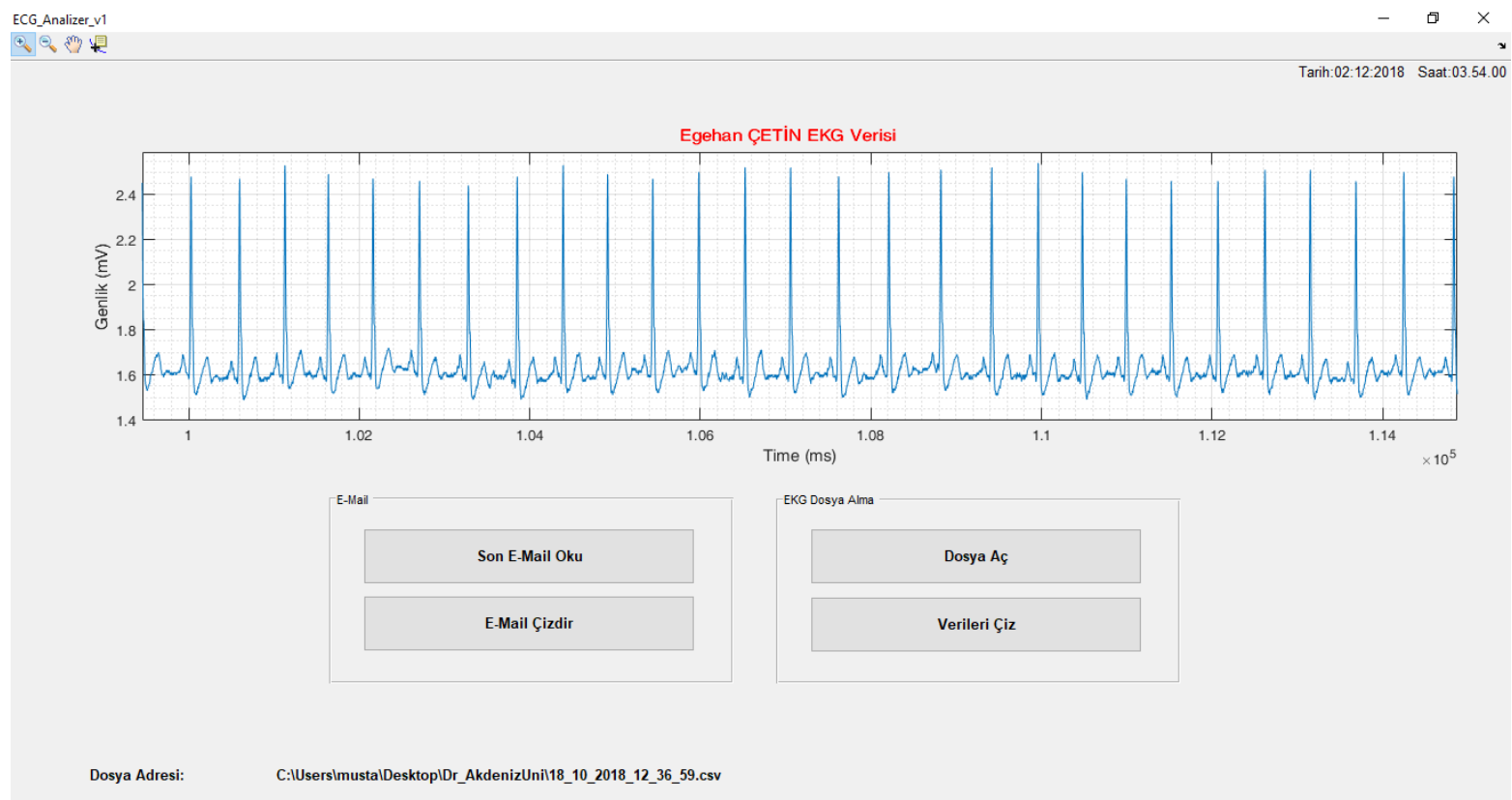

Şekil 20. E- Mail'e gelen EKG dosyasının gösterilmesi 


\section{BULGULAR VE TARTIŞMA}

Bu çalışmada üzerinde durulan Biyomedikal ve Telemetri alanları üzerine birçok çalışma bulunmaktadır. Bu alan üzerinde gerçekleştirilen sistemler ve gelişmeler sayesinde insan sağlığı ve hastalık teşhisi üzerinde sağladığı faydalar insan hayatının kalitesini arttırmaktadır.

Bu amaç doğrultusunda literatür taramasında bahsedildiği gibi birçok çalışma ile bahsi geçen konuya katkı sağlamıştır. Çalışmalar biyolojik sinyallerin alınması, görüntülenmesi, kaydedilmesi, gönderilmesi, analiz edilmesi, sınıflandırılması, yapay zekâ sistemleri kullanılarak hastalık teşhisi gibi birçok alanda yapılarak bilime katkı sağlamışlardır. Kablosuz biyomedikal sinyal iletilmesi ve kaydedilmesi gibi çalışmalar hastalara bağlanan karmaşık kablo bağlantılarını azaltmasına ve biyomedikal sinyallerin akıllı telefon veya sinyal izleme merkezleri gibi noktalara iletilmesini kolaylaştırmıştır. Bu konuda yapılan çalışmalar sayesinde hasta günlük hayatına devamını gerçekleştirirken verileri uzak noktadaki uzman kişi ya da kişilere kısa sürede ulaşması sağlanmaktadır. Böylece kısa sürede hastalık teşhisi ve müdahale süresini azaltılmaktadır.

Bu çalışmayı diğer çalışmalardan ayıran özelliklerini sıralamak gerekirse üç ayrı bölümden oluşması ve her bölümün birbirinden ayrı platformda gerçekleşmesi ve tüm sistemin birleşik çalışmasıdır.

Illk aşama olan kablosuz EKG alıcı devresi boyut ve kullanış açısından basit olması sayesinde taşıması kolaydır. Hastanın günlük hayatının devamını sağlarken engel olması herhangi bir kabloyla bağlantısı olmaması aktivitelerini kısıtlamamasını sağlamaktadır. Tasarımda kullanılan batarya sayesinde devrede gerçekleştirilmesi gereken $50 \mathrm{~Hz}$ çentik filtre tasarımı kullanılmamıştır. Verilerin kablosuz gönderim aşamasında Bluetooth kullanııması bağlantı sağladığı alan içerisinde kişinin EKG verisinin alınmasını kolaylaştırmaktadır. Tasarımda kullanılan Organik Led ekran sayesinde daha düşük enerji tüketiminin yanı sıra kişi günlük hayatında normal bir kol saati gibi kullanmasını sağlamaktadır. Gerçekleştirilen tasarım sayesinde hastanın psikolojik olarak daha rahat olması hedeflenmiştir.

İkinci aşamada Android ara yüz uygulaması gerçekleştirilerek hasta EKG verilerinin gerçek zamanlı olarak akıllı telefon ekranında görüntülenmesi, kaydedilmesi ve hekim E-mail adresin gönderilmesi sağlanmıştır. Android' de gerçekleştirilen uygulama sayesinde kablosuz EKG alıcı devresi ile aralarında anlık olarak EKG grafiğini görüntülenmesi tek kanallı hasta başı monitör olarak kullanım imkânı sağlamaktadır. Aynı zamanda akıllı telefonlarda ek uygulamalar kullanılarak hastanın akıllı telefo- nuna uzaktan erişim imkânı sağlayarak hasta takip sistemi olarak kullanılma imkânı sağlamaktadır. Bu sayede gerek hekim gerekse hasta yakınları hastanın EKG kaydını gözlemleme, kaydetme ve gönderme imkânına sahip olmaktadır.

Hekim bilgisayarına kurulan ara yüz sayesinde otomatik E-mail kontrolü sağlanmıştır. E-mail bilgisayara geldiğinde hasta EKG verisinin bilgisayara indirilmesi sağlanarak hasta verilerinin zaman kaybetmeden bilgisayar ekranında görüntülenmesi sağlanmıştır. Her yeni gelen EKG verisi sesli uyarı sistemi sayesinde hekimin dikkatinin çekilmesi sağlanarak ivedilikle incelenmesi sağlanmıştır.

Bu çalışma sayesinde hasta hekim arasındaki ilişki en aza indirgenmesi sağlanmış olacaktır. Bu sayede hastaların tedavi süreçlerinin takibi kolaylaşacak, kalp rahatsızlığı olma intimali olan kişilerin rahatsızlık hissettikleri anın kaydını hekime göndermesi ile kişilere doğru erken tanı ve teşhis imkânı sayesinde tedavi başlama süresi hızlanacaktır.

\section{SONUÇLAR}

Gerçekleştirilen sistem sayesinde kalp rahatsızlığı olan veya olma intimali bulunan hastaların günlük hayatlarının devamlılığını sürdürürken rahatsızlık hissettikleri anların kayıtlarını anlık olarak alınabilecektir. Hekimin Email adresine EKG verisini göndererek kişinin hekime gitmeden durumunun değerlendirilebilmesine imkân sağlayacaktır. Bu sayede hastalar günlük aktivitelerini bölünmeden sürdürebilecek, hastanelerdeki bekleme ve düzensizlikten kaynaklı hasta yoğunluğunun azaltmasına yardımcı olunacaktır.

Hekim için gerçekleştirilen bilgisayar ara yüzü ile hekim hastanın rahatsız olduğu andaki EKG verisini E-mail adresini sürekli kontrol etmesine gerek kalmadan inceleme imkânı sağlayabilecektir. Gerçekleştirilen bilgisayar ara yüzü sayesinde hekim bilgisayar başında olmasa bile sesli uyarı sayesinde hastaya ait yeni EKG verisinin geldiğini belirtmekte ve hekimin uyartımı sağlanmaktadır.

Çalışma hekim-hasta ilişkisini en aza indirerek hastalık teşhisinin doğruluğuna katkı sağlamakta ve teşhis sürecinin kısaltılmasına imkan yaratmaktadır. Aynı zamanda hastalarını takibi ve gelişmeleri gözlemlenerek hastalık durumlarının ilerleme ve gerilemelerini zaman kaybetmeden yapılmasına olanak sağlamaktadır. Kablosuz EKG alıcı ve Android ara yüz uygulaması sayesinde cihaz hasta başı monitörü olarak kullanım imkânı sağlayarak hastanın EKG sinyali anlık olarak görüntülenme 
imkânı sağlamaktadır. Cihazın küçük ve taşınabilir olması sayesinde EKG görüntüleme gerektiren durumlarda kullanılabilmektedir.

\section{KAYNAKLAR}

Aktürk, T. B. (2009). PDA Tabanlı Gerçek Zamanlı EKG Görüntüleme Sistemi. Afyon Kocatepe Üniversitesi Fen Bilimleri Enstitüsü, Yüksek Lisans Tezi, Afyon.

Analog Devices (2021). Datasheet. https://www.analog.com/media/en/technical-documentation/datasheets/ad8232.pdf (Erişim Tarihi: 27.02.2021).

Bharathi, M. M., Belal, M. (2013). Wireless Transmission of Real Time Electrocardiogram (ECG) Signals through Radio Frequency (RF) Waves. International Journal of Scientific \& Engineering Research, 4(4):1471-1477.

Boskovic, A., Despotovic, M. (2005). An efficient approach to ECG signal transmission via GPRS. In EUROCON 2005The International Conference: Computer as a Tool, November, 2005, 1:76-79. IEEE.

Chandini, H. P., Mangala, H. D., Sapna, C. L., Manojkumar, S. B. (2018). ECG Telemetry System for loT Using Raspberry $\mathrm{Pi}$. In International Journal of Engineering Research \& Technology (IJERT): NCESC-2018 Conference Proceedings, 6(13): 1-4.

Chatzigiannakis, I., Valchinov, E. S., Antoniou, A., Kalogeras, A., Alexakos, C., Konstantinopoulos, P. (2015). Advanced observation and telemetry heart system utilizing wearable ECG device and a Cloud platform. In 2015 IEEE Symposium on Computers and Communication (ISCC), July, 2015, 25-30.

Çakır, L. (2014). Elektrokardiyogram (EKG) İşaretlerinin Optik Biyotelemetri Kullanarak İletilmesi. Gazi Üniversitesi Fen Bilimleri Enstitüsü, Yüksek Lisans Tezi, Ankara.

Çalıkuşu, İ. (2012). Design and Development of a Medical Telemetry System. Near East University, Unpublished PhD Dissertation, Nicosia.

Cunedioğlu, U. (2007). Aliev-panfilov modeli kullanarak kalbin elektriksel aktivitesinin 3-boyutlu simülasyonu. Başkent Üniversitesi Fen Bilimleri Enstitüsü, Yüksek Lisans Tezi, Ankara.

Elena, M., Quero, J. M., Toral, S., Tarrida, C. (2002). Cardiosmart: Intelligent Cardiology Monitoring System Using GPS/GPRS Networks. IEEE 2002 28 ${ }^{\text {th }}$ Annual Conference of the Industrial Electronics Society, November, 2002, Spain, 7762022: 3419-3424.

Fensli, R., Gunnarson, E., Gundersen, T. (2005). A wearable ECG-recording system for continuous arrhythmia monitoring in a wireless tele-home-care situation. $18^{\text {th }}$ IEEE symposium on computer-based medical systems, New Jersey: IEEE, 407-412.

Güler, N., Fidan, U. (2006). Wireless Transmission of ECG Signal. Journal of Medical Systems, 30(3): 231-235.

Hegazy, R. A., Lotfy, W. (2007). The value of holter monitoring in the assessment of pediatric patients. Indian Pacing Electrophysiol Journal, 7(4): 204-214.

Karpawich, P. P., Cavitt, D. L., Sugalski, J. S. (1993). Ambulatory arrhythmia screening in symptomatic children and young adults: comparative effectiveness of holter and telephone event recordings. Pediatric Cardiology, 14(3): 147150.

Keskin, E. H. (2018). UART Nedir ve Nasıl Çalışır? http://herenkeskin.com/uart-nedir-ve-nasil-calisir/[Son erişim tarihi: 27.02.2021].

Kocatürk, M. (2004). Design of A Wi-Fi Based Electrocardıography Monitoring System. ITÜ Fen Bilimleri Enstitüsü, Yüksek Lisans Tezi, İstanbul.

Lee, J. H., Seo, D. W. (2019). Development of ECG monitoring system and implantable device with wireless charging. Micromachines, 10(1): 38 .

Lin, B., Chou, N., Chong, F., Chen, S. (2006). Rtwpms: a realtime wireless physiological monitoring system. IEEE Transactions on Information Technology in Biomedicine, 10(4): 647-656.

Linzer, M., Pritchett, E. L., Pontinen, M., McCarthy, E., Divine, G. W. (1990). Incremental diagnostic yield of loop electrocardiographic recorders in unexplained syncope. The American Journal of Cardiology, 66(2): 214-219.

Liu, J., Xie, F., Zhou, Y., Zou, Q., Wu, J. (2013). A Wearable Health Monitoring System with Multi-Parameters. $6^{\text {th }}$ International Conference on Biomedical Engineering and Informatics, 2013, Hangzhou, 332-336.

Lucani, D., Cataldo, G., Cruz, J., Villegas, G., Wong, S. (2006). A portable ECG monitoring device with bluetooth and holter capabilities for telemedicine applications. $28^{\text {th }}$ annual international conference of the IEEE engineering in medicine and biology society, New Jersey: IEEE, 5244-5247.

Lv, Z., Xia, F., Wu, G., Yao, L., Chen, Z. (2010). Icare: a mobile health monitoring system for the elderly. IEEE/ACM Int'I Conference on Green Computing and Communications \& Int'l Conference on Cyber, Physical and Social Computing, New Jersey: IEEE, 699-705.

Mahdiani, S., Jeyhani, V., Peltokangas, M., Vehkaoja, A. (2015). Is $50 \mathrm{~Hz}$ high enough ECG sampling frequency for accurate HRV analysis? $37^{\text {th }}$ Annual International Conference of the IEEE Engineering in Medicine and Biology Society, August, 2015, 5948 - 5951.

Marouf, M., Vukomanovic, G., Saranovac, L., Bozic, M. (2017). Multi-purpose ECG telemetry system. BioMedical Engineering OnLine, Serbia 16(1): 1-20.

Özkaraca, O, Güler, I. (2015). Denoising and remote monitoring of ECG signal with real-time extended kalman filter in a wearable system. Biomedical Engineering: Applications, Basis and Communications, 27(1): 1550009.

Park, C., Chou, P. H. (2006). An Ultra-Wearable, Wireless, Low Power ECG Monitoring System. Biomedical Circuits and Systems Conference, IEEE, England,10146289, 241244.

Proulx, J., Clifford, R., Sorensen, S. (2006). Development and Evaluation of a Bluetooth EKG Monitoring Sensor. 19th IEEE Symposium on Computer-Based Medical Systems, USA, 9187352, 507-511p.

Russell, D. M., McCormick, D., Taberner, A. J., Malpas, S. C., Budgett, D. M. (2011). A high bandwidth fully implantable mouse telemetry system for chronic ECG measurement. 2011 Annual International Conference of the IEEE Engineering in Medicine and Biology Society, August, 76667669p. 
Şişman, C. (2017). Kablosuz IEEE 802.15. 6 haberleşmesi ile EKG ve solunum takip sistemi. Karadeniz Teknik Üniversitesi Fen Bilimleri Enstitüsü, Doktora Tezi, Trabzon.

Tseng, K., Lin, B., Liao, L., Wang, Y., Wang, Y. (2014). Development of a wearable mobile electrocardiogram monitoring system by using novel dry foam electrodes. IEEE systems Journal, 8(3): 900-6.

Türker, G. F., Tarımer, İ. (2016). Kablosuz algılayıcı ağ tabanlı taşınabilir EKG tasarımı ve uygulaması. Pamukkale University Journal of Engineering Sciences, 22(2).

Wu, C. C., Hsieh, M. H., Tai, C. T., Chiang, C. E., Yu, W. C., Lin, Y. K, Tsao, H. M., Ding, P. Y. A, Chen, S. A. (2003). Utility of patient-activated cardiac event recorders in the detection of cardiac arrhythmias. Journal of interventional cardiac electrophysiology, 8(2):117-20.

Xue,Y., Shuicai,W., Yanping, B. (2007). An ECG Wireless Monitoring Instrument Based on GPRS. International Conference on Complex Medical Engineering, China, 9720378, 238-241.
Yalman, S., Irmak, M. C., Haşıloğlu, A. (2015). A mobile-based approach to monitor biomedical signals. In 2015 Medical Technologies National Conference, IEEE, October, 2015, 1-4.

Zeybek, M. (2007). Real Time Acquisition and Wireless Transmission of ECG Signal. Dokuz Eylül Üniversitesi Fen Bilimleri Enstitüsü, Yüksek Lisans Tezi, İzmir.

Zhu, Q., Wang, M. (2006). A Wireless PDA-based Electrocardiogram Transmission System for Telemedicine. Engineering in Medicine and Biology Society, China, 9218680, 3807 -3809 .

Zimetbaum, P., Goldman, A. (2010). Ambulatory arrhythmia monitoring choosing the right device. Circulation, 122(16): 1629-36.

Zimetbaum, P. J., Kim K. Y., Josephson, M. E., Goldberger, A. L., Cohen, D. J. (1998). Diagnostic yield and optimal duration of continuous-loop event monitoring for the diagnosis of palpitations: a cost-effectiveness analysis. Annals of Internal Medicine, 128(11): 890-5. 